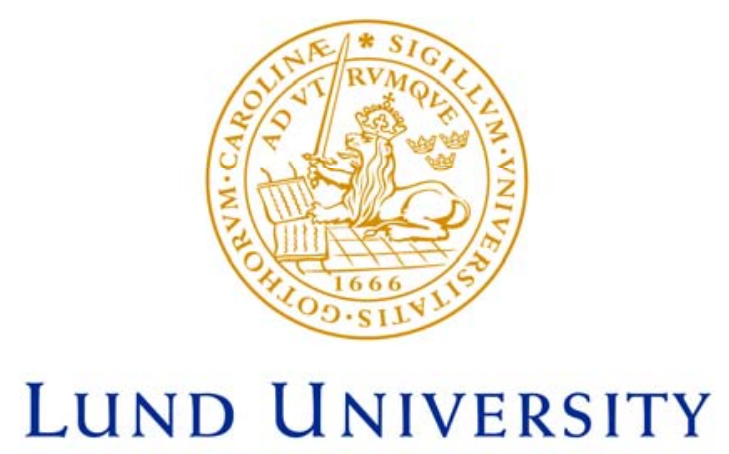

Faculty of Medicine

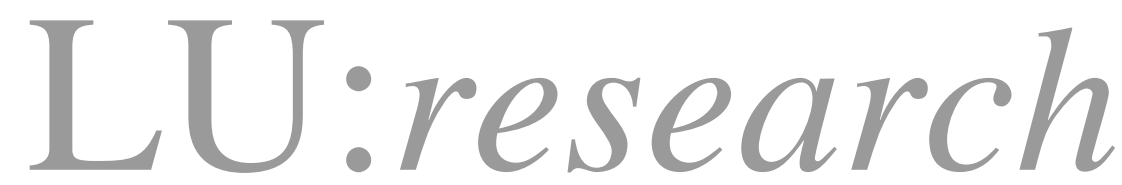

Institutional Repository of Lund University

This is an author produced version of a paper published in Biochimica et biophysica acta. This paper has been peerreviewed but does not include the final publisher proofcorrections or journal pagination.

Citation for the published paper:

Duan, R D and Verkade, H J and Cheng, $Y$ and Havinga, R and Nilsson, A.

"Effects of bile diversion in rats on intestinal sphingomyelinases and ceramidase."

Biochimica et biophysica acta, 2007, Vol: 1771, Issue: 2, pp. 196-201.

http://dx.doi.org/10.1016/j.bbalip.2006.12.001

Access to the published version may require journal subscription.

Published with permission from: Elsevier 


\title{
Effects of bile diversion in rats on intestinal sphingomyelinases and ceramidase
}

\author{
Duan $\mathrm{RD}^{1}$, Verkade $\mathrm{HJ}^{2}$, Cheng $\mathrm{Y}^{1}$, Havinga $\mathrm{R}^{2}$, Nilsson $\AA^{1}$. \\ 1.Gastroenterology Laboratory, Biomedical Center, B11, Lund University, Lund, Sweden \\ 2. Pediatric Gastroenterology, University Medical Center Groningen, University of Groningen, \\ Groningen, Netherlands.
}

Correspondence to

Rui-Dong Duan, MD, PhD

Gastroenterology Lab.

Biomedical Center, B11

Lund University

S-221 84 Lund

Sweden.

Tel. +46 462220709

Fax. +4646137277

Email: Rui-dong.duan@med.lu.se 


\section{Summary:}

Alkaline sphingomyelinase (Alk-SMase) and neutral ceramidase (N-CDase) in the intestinal microvillar membrane are responsible for dietary sphingomyelin digestion. The activities of the enzymes require the presence of bile salt, and the enzymes can be released into the gut lumen in active forms by bile salts and trypsin. It is unclear to what extent that the intestinal presence of bile salts is critical for the intraluminal activity of these enzymes. We compared the activities of Alk-SMase, N-CDase, and other types of SMases in control and permanently bile diverted rats. In the intestinal tract of control rats, the activity of Alk-SMase was profoundly higher than those of acid and neutral SMases. Bile diversion reduced Alk-SMase activity by $85 \%$ in the small intestinal content, and by $68 \%$ in the faeces, but did not significantly change the activity in the intestinal mucosa. Western blot showed a marked reduction of the enzyme in the intestinal lumen but not mucosa. N-CDase activities both in the intestinal mucosa and content were reduced by bile diversion. Bile diversion also decreased aminopeptidase $\mathrm{N}$ activity in the content and increased that in the mucosa, but had no effects on that of alkaline phosphatase. In conclusion, the presence of bile salts is important for maintaining high intraluminal levels of Alk-SMase and $\mathrm{N}-\mathrm{CD}$ ase, two key enzymes for hydrolysis of sphingomyelin in the gut. We speculate that the sphingomyelin hydrolysis in cholestatic conditions is impaired not only by reduced hydrolytic activity but also by deficient dissociation of the enzymes from the membrane.

Key words. Sphingomyelinase, ceramidase, bile diversion, rat, small intestine, colon. 


\section{Introduction}

Alkaline sphingomyelinase (Alk-SMase) and neutral ceramidase (N-CDase) are two enzymes important for step-wise digestion of SM in the intestinal tract. Sphingomyelin (SM) in the gut is first hydrolysed by Alk-SMase to ceramide that in turn further hydrolysed by N-CDase to sphingosine and fatty acid. The two enzymes are important regulators for intestinal concentration of ceramide and sphingosine, which have been considered as antiproliferative and apoptotic molecules $[1,2]$. Our laboratory has recently cloned intestinal Alk-SMase in both human and rats [3,4] and characterized intestinal N-CDase in the purified form [5]. The enzymes are ecto-enzymes that anchor on the brush border surface via a hydrophobic domain at the C-terminal for Alk-SMase and N-terminal for N-CDase [3, 6], and can be released in active form into the gut lumen $[3,5,7,8]$. We previously showed that Alk-SMase activity was significantly decreased in biopsies of human colon cancer and ulcerative colitis $[9,10]$ and have implications for tumorigenesis in the colon and cholesterol absorption in the small intestine, as recently reviewed [11].

Several previous studies have linked the enzyme to bile acid metabolism. First, bile salts, particularly taurocholic and taurochenodeoxycholic acids, strongly increase the activity of AlkSMase in vitro [12]. The bile salt seems to be a physiological activator for the enzyme and independent from its detergent activity, since synthetic detergents such as Triton X100 and CHAPS inhibit rather than activate Alk-SMase [12]. The presence of bile salts is also important for N-CDase activity, though the species specificity is less obvious than for Alk-SMase [5, 13]. Second, luminal perfusion of the small intestine or incubation of intestinal loops with bile salts releases both Alk-SMase and N-CDase into the gut lumen [5, 12, 14]. The hydrophobic anchoring of the enzymes in the membrane may be overcome by the detergent effect of bile salts. The activities of Alk-SMase and N-CDase are highest in the middle part of the small intestine where most of the SM digestion occurs, and the bile salts are not yet reabsorbed [13, 15]. Third, the expression of Alk-SMase can be induced by ursodeoxycholic acid both in rats [16] and in a human colon cancer derived cell line [17]. The effect is more potent on differentiated enterocytes than on proliferating cells. Another interesting feature of Alk-SMase is its biliary secretion in humans but not in other species, as convinced by activity assay, Western blot and Northern blot in our previous studies $[3,4,18,19]$. Bile salt dependent hydrolysis of SM in the gut lumen or in 
the brush border membrane may indirectly influence cholesterol absorption [20], which is highly dependent on bile salts.

We aimed to determine whether bile is of critical importance for the expression of AlkSMase and N-CDase in the intestinal mucosa, and for their release into the gut lumen. Our results indicate that the absence of bile may significantly reduce hydrolysis of SM and ceramide in gut lumen.

\section{Materials and Methods}

\section{Materials}

SM was purified from bovine milk and labelled with $\left[{ }^{14} \mathrm{C}-\mathrm{CH}_{3}\right]$ choline $\left(\left[{ }^{14} \mathrm{C}-\mathrm{SM}\right]\right)$ by Dr. Ström at Astra Zeneca (Stockholm, Sweden) [21]. Anti-human Alk-SMase antibody was developed in AgriSera AB (Vännäs, Sweden) using purified human Alk-SMase as an antigen [8]. Our preliminary studies found that this antibody cross reacts with rat intestinal alk-SMase. $1-{ }^{14} \mathrm{C}$ octanoyl-sphingosine was obtained from American Radiolabelled Chemicals, St Louis, MO, USA. All other agents used were purchased from Sigma. Co. (Stockholm, Sweden).

\section{Methods}

Male Wistar rats (Harlan, Zeist, The Netherlands), weighing 280 to 310 g, were housed in an environmentally controlled facility with diurnal light cycling and free access to standard rodent lab chow and tap water (and additional saline, $0.9 \% \mathrm{NaCl}$ w/v, in the case of bile-deficient rats). Experimental protocols were approved by the Ethical Committee for Animal Experiments, Faculty of Medical Sciences, University of Groningen. One group of rats $(n=4)$ were equipped with permanent catheters at the proximal common bile duct (bile-deficiency rats) and the bile was continuously drained (19). Animals were allowed to recover from surgery for 1 week, after which they were subjected to overnight fasting.

\section{Sample preparation}

Eight days after surgery, the rats were terminated by cardiac puncture under halothane anaesthesia and the intestinal tract of the rats was removed. The whole small intestine was 
longitudinally opened and the intestinal content was washed in $30 \mathrm{ml}$ saline containing $2 \mathrm{mM}$ benzamidine. After centrifugation at $15000 \mathrm{~g}$ for $10 \mathrm{~min}$ at $4{ }^{\circ} \mathrm{C}$, the supernatant was saved for analysis of the enzyme activity in the intestinal lumen. The intestinal mucosa was scraped and homogenized in $10 \mathrm{ml}$ lysis buffer containing $50 \mathrm{mM}$ Tris, $2 \mathrm{mM}$ EDTA, $6 \mathrm{mM}$ TDC, $1 \mathrm{mM}$ PMSF, $1 \mathrm{mM}$ benzamidine, and $0.5 \mathrm{mM}$ DTT, $\mathrm{pH}$ 7.4. The colon was longitudinally opened and washed in $10 \mathrm{ml}$ of saline. The mucosa of colon was scraped and homogenized in $2 \mathrm{ml}$ of the lysis buffer. The homogenates of small intestinal mucosa and colonic mucosa were centrifuged at $15000 \mathrm{~g}$ for $10 \mathrm{~min}$ at $4{ }^{\circ} \mathrm{C}$ and the supernatant was used for biochemical determinations. One piece of faecal sample was collected from each animal at the distal part of the colon. The faecal sample was dried under a hood overnight, weighed, and resuspended in $10 \mathrm{ml}$ of $0.15 \mathrm{M} \mathrm{NaCl}$ containing $2 \mathrm{mM}$ benzamidine. The suspension was centrifuged at $3000 \mathrm{~g}$ for $10 \mathrm{~min}$ and the supernatant was saved for biochemical analysis [14].

\section{SMase assays}

The activities of SMases were determined as described previously [22]. For Alk-SMase assay, $5 \mu \mathrm{l}$ samples were mixed with $95 \mu \mathrm{l}$ of $50 \mathrm{mM}$ Tris- $\mathrm{HCl}$ buffer, $\mathrm{pH} 9.0$, containing $0.15 \mathrm{M}$ $\mathrm{NaCl}, 2 \mathrm{mM}$ EDTA, $6 \mathrm{mM}$ taurocholate, and $0.80 \mu \mathrm{M}\left[{ }^{14} \mathrm{C}\right]$-choline labelled SM to a final volume of $100 \mu \mathrm{l}$, followed by incubation at $37{ }^{\circ} \mathrm{C}$ for $30 \mathrm{~min}$. The reaction was terminated by adding chloroform/methanol (2:1). After phase partition, the cleaved phosphocholine in the upper phase was counted by liquid scintillation, using Ready Gel (Beckman Coulter) scintillation fluid. The activities of neutral and acid SMase were measured similarly except small modifications of the buffers. Neutral SMase was assayed in $50 \mathrm{mM}$ Tris buffer containing $2 \mathrm{mM} \mathrm{MgCl}, 0.15 \mathrm{M}$ $\mathrm{NaCl}$, and $0.12 \%$ Triton X 100, $\mathrm{pH} 7.5$. Acid SMase was determined in 50mM Tris-maleate buffer containing $0.15 \mathrm{NaCl}$ and $6 \mathrm{mM}$ Triton $\mathrm{X}$ 100, $\mathrm{pH} 5.0$.

$\mathrm{N}-\mathrm{CD}$ ase activity was determined as described earlier [5, 23]. Briefly, ${ }^{14} \mathrm{C}$-octanoylsphingosine was taken to dryness under nitrogen and then sonicated on ice for $2 \mathrm{~min}$ in $50 \mathrm{mM}$ Tris-Maleate buffer pH 7.0 with $10 \mathrm{mM}$ sodium TC. The assay was started by mixing $10 \mu \mathrm{l}$ of sample with $90 \mu \mathrm{l}$ assay buffer containing substrate and then incubated at $37^{\circ} \mathrm{C}$ for $1 \mathrm{~h}$. The substrate added contained 22,000 dpm and 50 nmole ${ }^{14} \mathrm{C}$-octanoyl-sphingosine. The reaction was interrupted by adding $0.6 \mathrm{ml}$ methanol:chloroform:heptane in proportions 28:25:20 (v:v:v) and $0.2 \mathrm{ml} 0.05 \mathrm{M} \mathrm{K}_{2} \mathrm{CO}_{3} / \mathrm{K}_{2} \mathrm{~B}_{2} \mathrm{O}_{2} \mathrm{pH} 10$. After centrifugation at $10000 \mathrm{rpm}$ for $10 \mathrm{~s}$, an aliquot of 
$200 \mu 1$ of upper phase was taken for liquid scintillation counting. The total dpm in the upper phase was calculated.

\section{Western blotting of Alk-SMase.}

The Western blotting of Alk-SMase was performed as described [3]. $50 \mu 1$ of intestinal content or $75 \mu \mathrm{g}$ of proteins from mucosal homogenate were subjected to $10 \%$ SDS-PAGE and transferred to a nitrocellulose membrane. The membrane was blotted with anti-human AlkSMase antibody (1:5000) for $2 \mathrm{~h}$. After washing, the membranes were reacted with anti-rabbit IgG antibody conjugated with horseradish peroxidase for $1 \mathrm{~h}$. The Alk-SMase bands were identified by ECL advance reagents and the remitted light was recorded on Kodak X-ray film.

\section{Other biochemical determinations}

Aminopeptidase $\mathrm{N}$ activity was determined according to a method based on the ability of the enzyme to hydrolyse alanine-p-nitroanilide into p-nitroaniline [24]. The alkaline phosphatase was assayed as described before [16]. The protein was assayed using the DC protein assay kit obtained from Bio-Rad with bovine albumin as a standard. The activities of the enzymes analyzed in mucosal samples were adjusted to the protein levels in the samples, and those in the intestinal content were adjusted with the sample volume.

\section{Statistical analysis}

The results were presented as mean \pm standard error and the statistical significance was analyzed by unpaired Student $\mathrm{t}$ test. $\mathrm{P}<0.05$ was considered as statistically significant.

\section{Results}

SMase activity in the small intestine. Figure 1 shows the SMase activity in the intestinal content and mucosa in control and bile-deficient rats. Under physiological (control) conditions, the activity of Alk-SMase in the lumen was the highest followed by that of acid SMase. The activity of neutral SMase in the lumen was very low, being less than $1 \%$ of that of Alk-SMase. Bile diversion significantly reduced the activity of Alk-SMase in the lumen by $85 \%$ and that of acid SMase by $73 \%$. The low neutral SMase activity in the lumen increased $\sim 2$ fold by bile diversion to about $10 \%$ of Alk-SMase activity under that conditions. In the mucosa of small 
intestine, the activities of acid and neutral SMase were very low, being only about 1-3\% of that of Alk-SMase. Bile diversion had no significant effect on either alkaline or neutral SMase, and slightly increased acid SMase activity.

Western blotting was performed to address whether the decreased Alk-SMase activity in the intestinal content was caused by a decreased enzyme activity or decreased protein level (Fig.2). The result shows that bile diversion markedly decreased the enzyme levels in the intestinal content (upper panel) but not in the intestinal mucosa, indicating a net reduction of the enzyme protein in the lumen. In one control sample, Western blotting identified an additional band in the intestinal content but not in the intestinal mucosa. The reason for the appearance of this band is unknown.

N-Cdase and other brush border enzymes in the small intestine. N-CDase is distributed in parallel with Alk-SMase and is responsible for digestion of ceramide produced by the action of Alk-SMase in the gut. Fig. 3 shows the ceramidase activity in control and bile deficient rats. Bile diversion significantly reduced the enzyme activity in both intestinal content and mucosa to similar extent. Other brush border enzymes in the intestinal tract including aminopeptidase $\mathrm{N}$ and alkaline phosphatase were also analysed. As shown in Fig. 4, bile diversion reduced the activity of amino peptidase $\mathrm{N}$ in the intestinal content and increased that in the mucosa. No significant change for alkaline phosphatase activity in either small intestinal mucosa or in the small intestinal content could be identified under the conditions (data not shown).

SMase in the colonic mucosa and faeces. Table 1 shows the activities of three types of SMase in the colonic mucosa. No significant changes of Alk-SMase were found by bile diversion. The Alk-SMase activity in faeces, however, was significantly decreased by $68 \%$ by bile diversion (Table 2), whereas neutral and acid SMase activities in colonic mucosa or in the faeces were not changed.

\section{Discussion}

Our present data clearly underline the importance of intestinal bile for the hydrolytic capacities of SM-hydrolysing enzymes in the intestinal tract. Permanent biliary drainage reduces significantly the protein content and the activity of Alk-SMase in the intestinal content and faeces but not in the intestinal mucosa, without significant effects on acid or neutral SMase activity. Bile drainage also reduced the activity of N-CDase in both intestinal content and mucosa. The 
significant reduction of Alk-SMase and N-CDase activity in the intestinal lumen could affect the hydrolysis of SM and the generation of ceramide and sphingosine, which have been considered important factors regulating proliferation and apoptosis of the cells [25]. The similar levels of Alk-SMase in the small intestinal mucosa of the normal and bile diverted rats shown by Western blotting indicate that the expression of the enzyme does not critically required the presence of bile components, such as bile salts.

Bile diversion may decrease the SM-hydrolytic enzyme activity in the gut lumen by at least two mechanisms. First, intestinal epithelial cells proliferate and differentiate upon their migration from the bottom of the crypt to the top of the villi where they undergo apoptosis. Roy et al [26] examined the effect of biliary drainage on cell turnover in the gut and found a decreased proliferative cell pool and reduced cell shedding. The effects could be reversed by bile salts. The data suggest that bile acids constitute important regulatory factors influencing enterocyte proliferation, differentiation, migration, and loss. Alk-SMase is exclusively expressed in differentiated enterocytes [27] and the dissociation of the differentiated cells into the lumen is expected to have fundamental influence on the Alk-SMase levels in the gut. This may explain partly the reduced Alk-SMase and N-CDase activities in the small intestinal lumen caused by bile diversion. Second, bile salts could have a direct influence on the release of brush border enzymes into the intestinal lumen. Shiozaki et al [28] found that sucrase-isomaltase was solubilized by taurocholate, and that bile diversion significantly increased the amount of the enzyme in the mucosa. Such a bile salt-induced dissociation of brush border enzyme may also contribute to the decreased Alk-SMase and N-CDase in the intestinal lumen. We previously showed that injection of bile at physiological concentrations in rat intestinal loop significantly increased alk-SMase activity in the lumen. The effect was not associated with increase of lactate dehydrogenase activity, indicating that the effects were not caused by detergent-induced lysis or sloughing of enterocytes. The effect was maximal by undiluted bile but detectable when the bile was diluted by 8 times [14]. Bile induced dissociation of alk-SMase was most likely caused by bile salt, as bile salt at concentrations lower than the critical micelle concentration rapidly released AlkSMase from the mucosa of the loops without a parallel release of lactate dehydrogenase [14]. In the present study, we also found that bile diversion decreased the activity of aminopeptidase $\mathrm{N}$ in the intestinal content and increased it in the mucosa. Aminopeptidase N, like alk-SMase, is an ectoenzyme that anchors on the mucosa via its N-terminal transmembrane domain [29]. 
However, in this study, we did not find an accumulation of Alk-SMase in the mucosa by bile diversion. This may be caused by the different synthesis rate of the two enzymes, since the brush border enzyme levels are determined by both synthesis rate and turnover rate. A reduced synthesis rate by bile diversion could theoretically compensate for decreased release in the lumen, resulting in net similar mucosal protein contents.

The effect of bile diversion on intestinal brush border enzymes may also be enzyme specific. In the present study, we found that bile diversion decreased the activities of alk-SMase, $\mathrm{N}-\mathrm{CD}$ ase, and amino peptidase $\mathrm{N}$ activity in the intestinal content but not alkaline phosphatase. In the intestinal mucosa, when aminopeptidase $\mathrm{N}$ was increased, $\mathrm{N}-\mathrm{CD}$ ase was decreased and alkaline phosphatase and Alk-SMase were not changed. Previous studies also showed different responses of different brush border enzymes such as aminopeptidase, sucrase-isomaltase, and alkaline phosphatase to cholestyramine or bile diversion [30]. The diversity could be related both to the way by which these enzymes bind on the brush border and to the alternations of synthesis rate of the enzymes. For example, alkaline phosphatase, which differing from many other brush border enzymes, binds the membrane with an covalent linkage to the phosphatidylinositol [29]. Bossman and Haschen [31] reported that during intestinal perfusion with bile salt, alanine aminopeptidase, alkaline phosphatase, $\gamma$-glutamyltransferase and enteropeptidase were all released, and an increased proportion originating from de novo synthesis was found. Although we presently did not find changes of Alk-SMase in the mucosa when the release of the enzyme to the lumen was decreased, we found decreased levels of N-CDase in both intestinal mucosa and lumen. The results support the view that, although Alk-SMase and N-CDase are closely related, the synthesis rate and/or release rate of N-CDase is not parallel to that of Alk-SMase. This is also in agreement with our previous study with psyllium, which increased Alk-SMase levels but decreased N-CDase levels in the intestinal mucosa after oral administration in mice [32].

Our data also showed that bile diversion profoundly decreases Alk-SMase activity in faeces. Theoretically, this could be due to decreased colonic expression, and/or secondary to decreased release of the enzyme in the small intestine, as Alk-SMase is extremely resistant to the pancreatic proteases present in the gut lumen and faeces [15]. The activity in the colon may contribute to colonic generation of sphingolipid metabolites that have been ascribed an antitumour effect $[9,33,34]$. By inference, the reduced Alk-SMase in the colon by bile diversion may be of interest to further delineate its potential implications in colonic tumorigenesis or 
tumour promotion. Two previous studies showed an increased proliferation and tumorigenesis in the gut by pancreaticobiliary diversion in animal studies [35, 36].

Decrease luminal activities of Alk-SMase and N-CDase may have secondary effects on cholesterol absorption. Even in intact rats with normal bile salt levels [20] and in studies on Caco2 cells with micellar solutions [37], SM was shown to inhibit cholesterol absorption, probably related to its strong physical interaction with sterols. A decreased capacity of luminal hydrolysis of SM may enhance the poor micellar solubilization of cholesterol in bile salt deficiency, a condition where the cholesterol absorption is very low. Field and co-workers reported that SMase influences both cholesterol absorption [38] and secretion of apoB containing lipoproteins in Caco2 cells [39], providing another potential link between SM metabolism and the effects of biliary drainage on lipoprotein secretion in the gut.

In conclusion, bile diversion significantly lowers Alk-SMase and N-CDase in the gut lumen. This, in combination with the deficient activation of the enzymes in the absence of bile salts, may significantly decrease production of sphingolipid metabolites, which may have implications in intestinal cell proliferation and cholesterol absorption. The present data also indicate that the absorption of SM in cholestatic conditions is not just compromised by reduced hydrolytic capacity, but additionally by impaired release of the enzyme to the lumen.

\section{Acknowledgement}

The work was supported by the grants from Swedish Research Council (03969), The Swedish Cancer Society, the Albert Påhlsson Foundation and the research foundation of University Hospital of Lund, Sweden. Henkjan Verkade is a Fellow of the Royal Netherlands Academy for Arts and Sciences. 


\section{References}

[1] R.N. Kolesnick, Sphingomyelin and derivatives as cellular signals, Prog Lipid Res 30 (1991) 1-38.

[2] Y.A. Hannun, The sphingomyelin cycle and the second messenger function of ceramide, J Biol Chem 269 (1994) 3125-3128.

[3] R.D. Duan, T. Bergman, N. Xu, J. Wu, Y. Cheng, J. Duan, S. Nelander, C. Palmberg, A. Nilsson, Identification of Human Intestinal Alkaline Sphingomyelinase as a Novel Ectoenzyme Related to the Nucleotide Phosphodiesterase Family, J Biol Chem 278 (2003) 38528-38536.

[4] J. Wu, Y. Cheng, C. Palmberg, T. Bergman, A. Nilsson, R.D. Duan, Cloning of alkaline sphingomyelinase from rat intestinal mucosa and adjusting of the hypothetical protein XP_221184 in GenBank, Biochim Biophys Acta 1687 (2005) 94-102.

[5] M. Olsson, R.D. Duan, L. Ohlsson, A. Nilsson, Rat intestinal ceramidase: purification, properties, and physiological relevance, Am J Physiol Gastrointest Liver Physiol 287 (2004) G929-937.

[6] J. Wu, G.H. Hansen, A. Nilsson, R.D. Duan, Functional studies of human intestinal alkaline sphingomyelinase by deglycosylation and mutagenesis, Biochem J 386 (2005) 153-160.

[7] A. Nilsson, The presence of sphingomyelin- and ceramide-cleaving enzymes in the small intestinal tract., Biochim Biophys Acta 176 (1969) 339-347.

[8] R.D. Duan, Y. Cheng, G. Hansen, E. Hertervig, J.J. Liu, I. Syk, H. Sjostrom, A. Nilsson, Purification, localization, and expression of human intestinal alkaline sphingomyelinase, $\mathrm{J}$ Lipid Res 44 (2003) 1241-1250.

[9] E. Hertervig, A. Nilsson, L. Nyberg, R.D. Duan, Alkaline sphingomyelinase activity is decreased in human colorectal carcinoma, Cancer 79 (1997) 448-453.

[10] U. Sjöqvist, E. Hertervig, A. Nilsson, R.D. Duan, A. Ost, B. Tribukait, R. Lofberg, Chronic colitis is associated with a reduction of mucosal alkaline sphingomyelinase activity, Inflamm Bowel Dis 8 (2002) 258-263.

[11] R.D. Duan, Alkaline sphingomyelinase: An old enzyme with novel implications, Biochim Biophys Acta 1761 (2006) 281-291.

[12] Y. Cheng, Å. Nilsson, E. Tömquist, R.D. Duan, Purification, characterization and expression of rat intestinal alkaline sphingomyelinase, J Lipid Res 43 (2002) 316-324.

[13] P. Lundgren, Å. Nilsson, R.D. Duan, Distribution and properties of neutral ceramidase activity in rat intestinal tract, Dig Dis Sci 46 (2001) 765-772.

[14] R.D. Duan, Y. Cheng, H.D. Tauschel, A. Nilsson, Effects of ursodeoxycholate and other bile salts on levels of rat intestinal alkaline sphingomyelinase: a potential implication in tumorigenesis, Dig Dis Sci 43 (1998) 26-32.

[15] R.D. Duan, L. Nyberg, A. Nilsson, Alkaline sphingomyelinase activity in rat gastrointestinal tract: distribution and characteristics, Biochim Biophys Acta 1259 (1995) 49-55.

[16] Y. Cheng, H.-T. Tauschel, Å. Nilsson, R.-D. Duan, Administration of ursodeoxycholic acid increases the activities of alkaline sphingomyelinase and caspase- 3 in rat colon, Scand J Gastroenterol 34 (1999) 915-920.

[17] F. Liu, Y. Cheng, J. Wu, H.D. Tauschel, R.D. Duan, Ursodeoxycholic acid differentially affects three types of sphingomyelinase in human colon cancer Caco 2 cells, Cancer Lett 235 (2006) 141-146. 
[18] L. Nyberg, R.D. Duan, J. Axelsson, Å. Nilsson, Identification of an alkaline sphingomyelinase activity in human bile, Biochim Biophys Acta 1300 (1996) 42-48.

[19] R.D. Duan, E. Hertervig, L. Nyberg, T. Hauge, B. Sternby, J. Lillienau, A. Farooqi, A. Nilsson, Distribution of alkaline sphingomyelinase activity in human beings and animals. Tissue and species differences, Dig Dis Sci 41 (1996) 1801-1806.

[20] L. Nyberg, R.D. Duan, Å. Nilsson, A mutual inhibitory effect on absorption of sphingomyelin and cholesterol, J Nutr Biochem 11 (2000) 244-249.

[21] W. Stoffel, Chemical synthesis of choline-labeled lecithins and sphingomyelin., Methods Enzymol 36 (1975) 533-541.

[22] R.D. Duan, A. Nilsson, Sphingolipid hydrolyzing enzymes in the gastrointestinal tract, Methods Enzymol 311 (2000) 276-286.

[23] R.D. Duan, Y. Cheng, L. Yang, L. Ohlsson, A. Nilsson, Evidence for specific ceramidase present in the intestinal contents of rats and humans, Lipids 36 (2001) 807-812.

[24] A.A. Amoscato, J.W. Alexander, G.F. Babcock, Surface aminopeptidase activity of human lymphocytes. I. Biochemical and biologic properties of intact cells, J Immunol 142 (1989) $1245-1252$.

[25] Y.A. Hannun, C.M. Linardic, Sphingolipid breakdown products: anti-proliferative and tumor- suppressor lipids, Biochim Biophys Acta 1154 (1993) 223-236.

[26] C.C. Roy, G. Laurendeau, G. Doyon, L. Chartrand, M.R. Rivest, The effect of bile and of sodium taurocholate on the epithelial cell dynamics of the rat small intestine, Proc Soc Exp Biol Med 149 (1975) 1000-1004.

[27] J. Wu, Y. Cheng, A. Nilsson, R.D. Duan, Identification of one exon deletion of intestinal alkaline sphingomyelinase in colon cancer HT-29 cells and a differentiation-related expression of the wild-type enzyme in Caco-2 cells, Carcinogenesis 25 (2004) 1327-1333.

[28] H. Shiozaki, M. Yoshioka, S. Miura, H. Imaeda, A. Morita, H. Asakura, M. Tsuchiya, H. Ishii, Conjugated bile salts regulate turnover of rat intestinal brush border membrane hydrolases, Dig Dis Sci 40 (1995) 1193-1198.

[29] S. Maroux, E. Coudrier, H. Feracci, J.P. Gorvel, D. Louvard, Molecular organization of the intestinal brush border, Biochimie 70 (1988) 1297-1306.

[30] K. Sonoyama, S. Kiriyama, R. Niki, Cholestyramine and bile diversion lower the aminopeptidase activity in the intestinal brush border membrane of rats, J Nutr Sci Vitaminol (Tokyo) 39 (1993) 617-625.

[31] B. Bossmann, R.J. Haschen, De novo synthesis of brush border membrane enzymes during intestinal perfusion with bile salt in the rat, J Clin Chem Clin Biochem 22 (1984) 449-451.

[32] Y. Cheng, L. Ohlsson, R.D. Duan, Psyllium and fat in diets differentially affect the activities and expressions of colonic sphingomyelinases and caspase in mice, $\mathrm{Br} \mathrm{J}$ Nutr 91 (2004) 715-723.

[33] E. Hertervig, Nilsson.Å., J. Björk, R. Hultkrantz, R.D. Duan, Familial adenomatous polyposis is associated with a marked decrease in alkaline sphingomyelinase activity; a key factor to the unrestrained cell proliferation, Br J Cancer 81 (1999) 232-236.

[34] E. Hertervig, A. Nilsson, Y. Cheng, R.D. Duan, Purified intestinal alkaline sphingomyelinase inhibits proliferation without inducing apoptosis in HT-29 colon carcinoma cells, J Cancer Res Clin Oncol 129 (2003) 577-582.

[35] R.C. Williamson, F.L. Bauer, J.S. Ross, J.B. Watkins, R.A. Malt, Enhanced colonic carcinogenesis with azoxymethane in rats after pancreaticobiliary diversion to mid small bowel, Gastroenterology 76 (1979) 1386-1392. 
[36] M. Chu, J.F. Rehfeld, K. Borch, Colonic mucosal proliferation after pancreaticobiliary diversion in the hamster, Dig Dis Sci 38 (1993) 1978-1984.

[37] E.R. Eckhardt, D.Q. Wang, J.M. Donovan, M.C. Carey, Dietary sphingomyelin suppresses intestinal cholesterol absorption by decreasing thermodynamic activity of cholesterol monomers, Gastroenterology 122 (2002) 948-956.

[38] H. Chen, E. Born, S.N. Mathur, F.C. Johlin, Jr., F.J. Field, Sphingomyelin content of intestinal cell membranes regulates cholesterol absorption. Evidence for pancreatic and intestinal cell sphingomyelinase activity, Biochem J 286 (1992) 771-777.

[39] F.J. Field, H. Chen, E. Born, B. Dixon, S. Mathur, Release of ceramide after membrane sphingomyelin hydrolysis decreases the basolateral secretion of triacylglycerol and

apolipoprotein B in cultured human intestinal cells, J Clin Invest 92 (1993) 2609-2619. 


\section{Figure legend}

Fig 1. Changes of SMase in the intestinal content (upper panel) and mucosa (lower panel). The whole intestinal tract was removed from the control and the bile diversion rats. The intestinal content was washed out in $30 \mathrm{ml}$ washing buffers and the mucosa was scraped and homogenised in $10 \mathrm{ml}$ of lysis buffer. The acid, neutral and alkaline SMase activities in both the content and the mucosa were determined using $\left[{ }^{14} \mathrm{C}-\mathrm{SM}\right]$ as substrate. Results are from 4 rats in each group. * $\mathrm{p}<0.05, * * \mathrm{p}<0.01$ and $* * * \mathrm{p}<0.001$ compared with the control.

Fig. 2. Western blotting of Alk-SMase in the intestinal content (upper panel) and mucosa (lower panel). $50 \mu \mathrm{l}$ of intestinal content or $75 \mu \mathrm{g}$ of proteins from mucosal homogenate were subjected to $10 \%$ SDS-PAGE and transferred to a nitrocellulose membrane, followed by incubation with anti-human Alk-SMase antibody (1:5000) and anti-rabbit IgG antibody conjugated with horseradish peroxidase. The Alk-SMase bands were identified by ECL advance reagents and the remitted light was recorded on Kodak X-ray film.

Fig. 3. Changes of neutral ceramidase activity in the intestinal content (upper panel) and mucosa (lower panel). The small intestine was removed from the control and the bile diversion rats. The intestinal content was washed out in $30 \mathrm{ml}$ washing buffers and the mucosa was scraped and homogenised in $10 \mathrm{ml}$ of lysis buffer. The neutral ceramidase activities in both the content and

the mucosa were determined using $\left[{ }^{3} \mathrm{H}\right] \mathrm{C} 8$-ceramide as substrate. Results are from 4 rats in each group. $* * \mathrm{p}<0.01$ and $* * * \mathrm{p}<0.001$ compared with the control rats.

Fig. 4. Changes of aminopeptidase $\mathrm{N}$ activity in the intestinal content (upper panel) and mucosa (lower panel). The small intestinal content from the animals was washed out in $30 \mathrm{ml}$ buffer and the mucosa was scraped and homogenized in $10 \mathrm{ml}$ lysis buffer. The activity of aminopeptidase in both content and mucosa were determined using alanine-p-nitroanilide as substrate. Results are from 4 rats in each group. ${ }^{*} \mathrm{p}<0.05$ compared with the control rats. 
g. 1 .
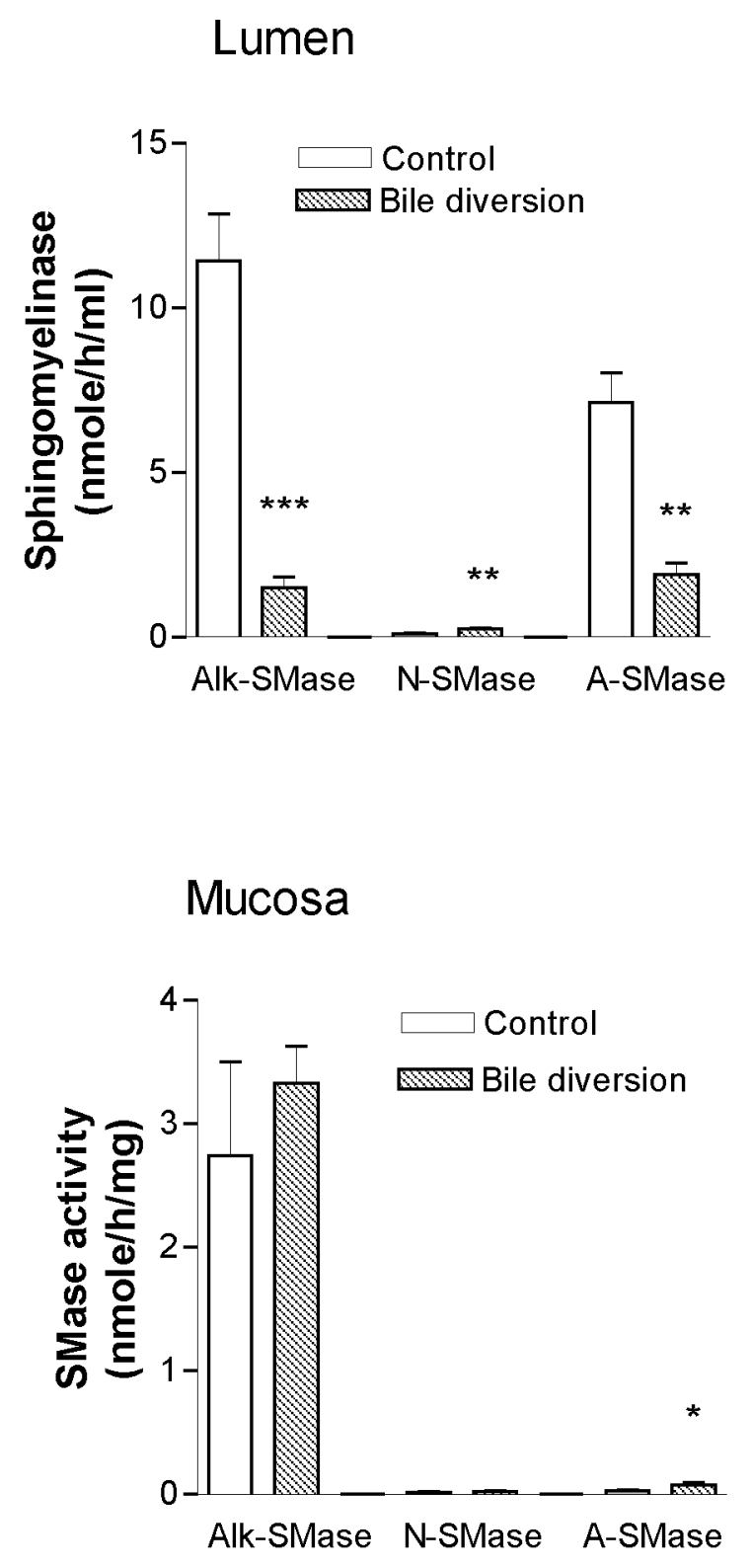
Fig. 2

Lumen

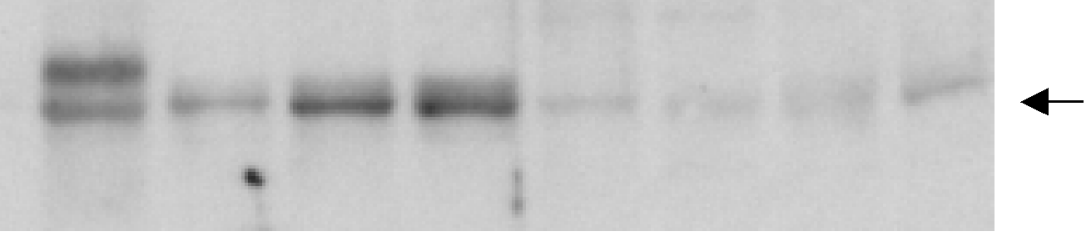

Mucosa

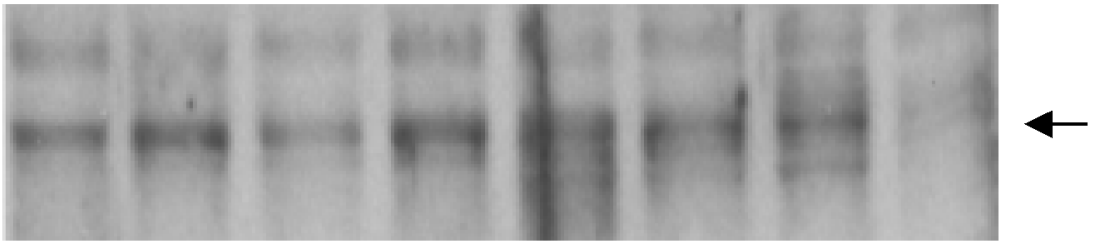

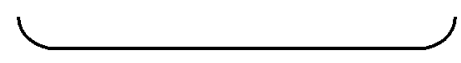

Control

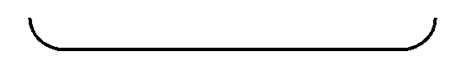

Bile diversion 
Fig. 3
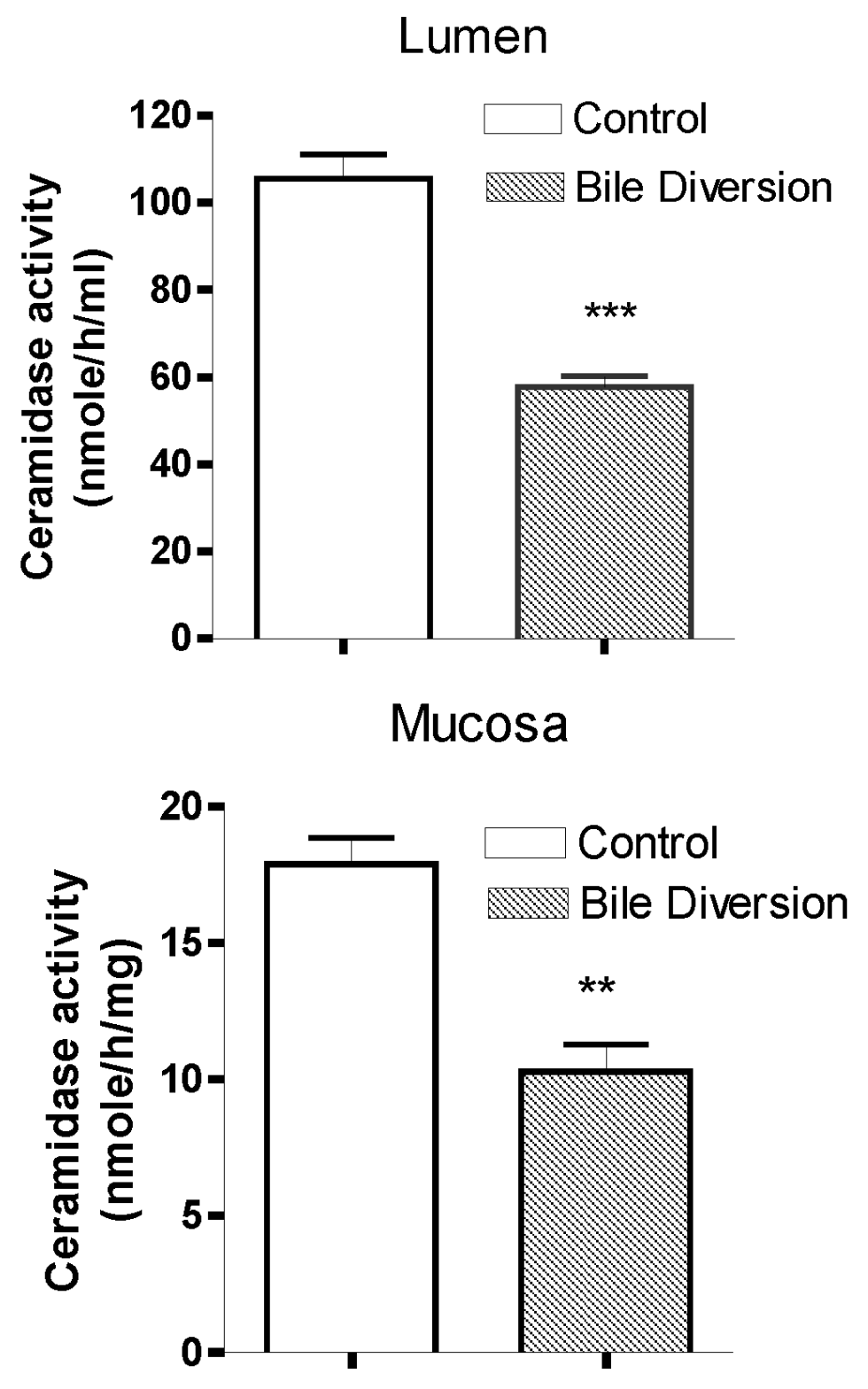
Fig. 4.
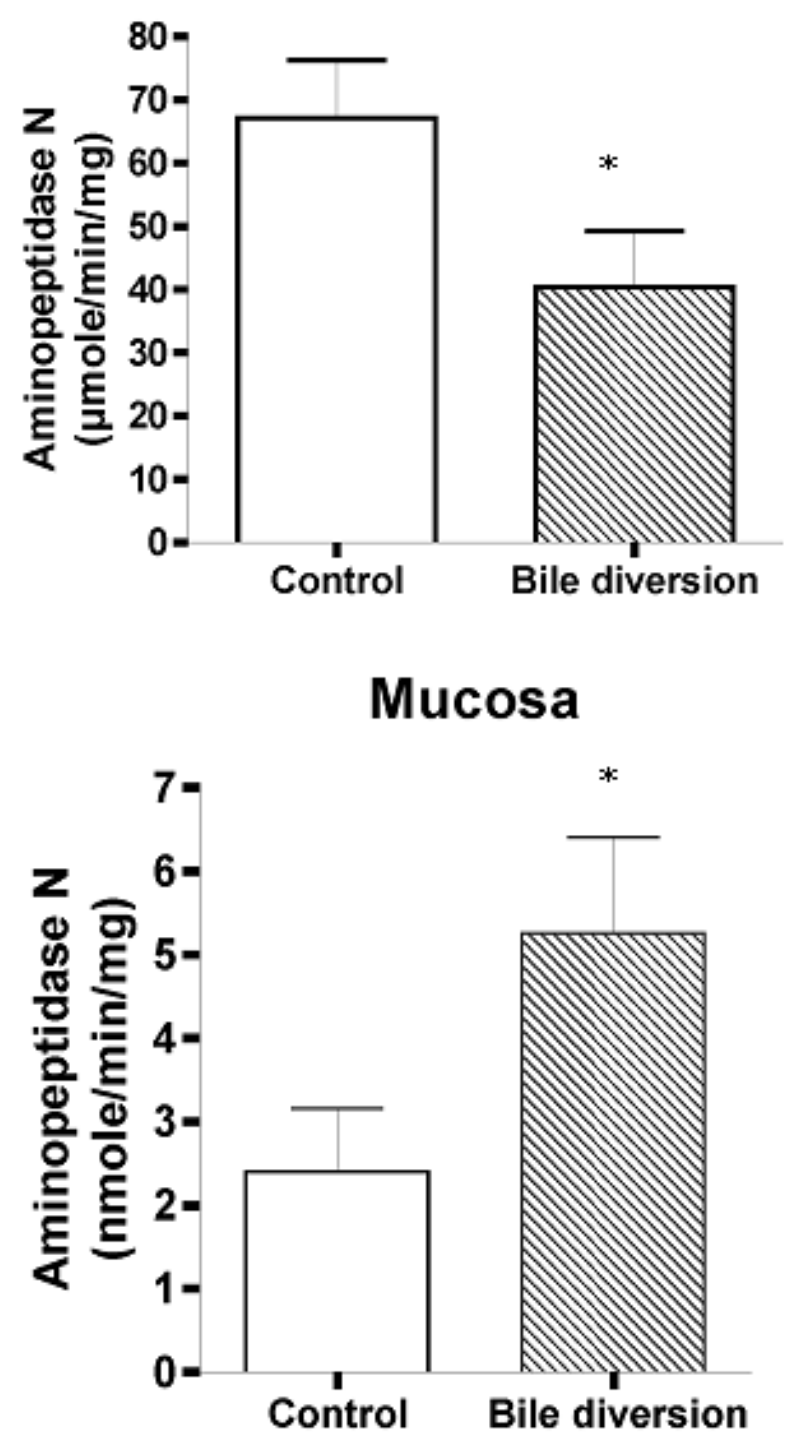
Table 1. Changes of sphingomyelinase activity in colonic mucosa induced by bile diversion

\begin{tabular}{llll} 
& $\begin{array}{l}\text { Alk-SMase } \\
\text { (pmole/h/mg) }\end{array}$ & $\begin{array}{l}\text { N-SMase } \\
(\mathrm{pmole} / \mathrm{h} / \mathrm{mg})\end{array}$ & $\begin{array}{l}\text { A-SMase } \\
(\mathrm{pmole} / \mathrm{h} / \mathrm{mg})\end{array}$ \\
\hline Control & $580 \pm 240$ & $34.8 \pm 7.8$ & $196 \pm 39.8$ \\
Bile diversion & $290 \pm 60$ & $48.5 \pm 6.3$ & $257 \pm 41.8$
\end{tabular}

The colonic mucosa from control and the bile diverted rats were scraped, homogenized and sonicated. After centrifugation the activities of acid SMase (A-SMase), neutral SMase (N-SMase) and alkaline SMase (Alk-SMase) were determined. $\mathrm{N}=4$ in each group.

Table 2. Changes of sphingomyelinase activity in faeces after bile diversion

\begin{tabular}{llll} 
& $\begin{array}{l}\text { Alk-SMase } \\
(\mathrm{pmole} / \mathrm{h} / \mathrm{mg})\end{array}$ & $\begin{array}{l}\mathrm{N}-\mathrm{SMase} \\
(\mathrm{pmole} / \mathrm{h} / \mathrm{mg})\end{array}$ & $\begin{array}{l}\text { A-SMase } \\
(\mathrm{pmole} / \mathrm{h} / \mathrm{mg})\end{array}$ \\
\hline Control & $1140 \pm 210$ & $107 \pm 12.4$ & $113 \pm 29$ \\
Bile diversion & $370 \pm 60 *$ & $95.0 \pm 27.9$ & $121 \pm 15.7$
\end{tabular}

The faecal samples from control and the bile diverted rats were collected, dried and homogenized as described in the Method section. After centrifugation the activities of acid SMase (A-SMase), neutral SMase (N-SMase) and alkaline SMase (Alk-SMase) in the supernatant were determined. $\mathrm{N}=4$ in each group. $* \mathrm{p}<0.05$ compared with control. 